\title{
Association between low-density cholesterol change and outcomes in acute ischemic stroke patients who underwent reperfusion therapy
}

Ting Cui ${ }^{1+}$, Changyi Wang ${ }^{1,2+}$, Qiange Zhu ${ }^{3}$, Anmo Wang ${ }^{1}$, Xuening Zhang ${ }^{1}$, Shucheng Li ${ }^{1}$, Yuan Yang ${ }^{1}$, Wenzuo Shang ${ }^{1}$, Rong Peng ${ }^{1 *}$ and Bo Wu ${ }^{1 *}$

\begin{abstract}
Background: Low-density lipoprotein cholesterol (LDL-C) can increase cardiovascular risk. However, the association between LDL-C change and functional outcomes in acute ischemic stroke (AIS) patients who underwent reperfusion therapy remains unclear.

Methods: Patients who received reperfusion therapy were consecutively enrolled. LDL-C measurement was conducted at the emergency department immediately after admission and during hospitalization. The change of LDL$C$ level $(\triangle L D L-C)$ was calculated by subtracting the lowest $L D L-C$ among all measurements during hospitalization from the admission LDL-C. Poor functional outcome was defined as modified Rankin Scale (mRS) > 2 at 90 days.

Results: A total of 432 patients were enrolled (mean age $69.2 \pm 13.5$ years, $54.6 \%$ males). The mean LDL-C level at admission was $2.55 \pm 0.93 \mathrm{mmol} / \mathrm{L}$. The median $\Delta \mathrm{LDL}-\mathrm{C}$ level was $0.43 \mathrm{mmol} / \mathrm{L}$ (IQR $0.08-0.94 \mathrm{mmol} / \mathrm{L})$. A total of 263 (60.9\%) patients had poor functional outcomes at 90 days. There was no significant association between admission LDL-C level and functional outcome (OR 0.99, $95 \% \mathrm{Cl} 0.77-1.27, p=0.904)$. $\Delta$ LDL-C level was positively associated with poor functional outcome $(\mathrm{OR} 1.80,95 \% \mathrm{Cl} 1,12-2.91, p=0.016)$. When patients were divided into tertiles according to $\Delta \mathrm{LDL}-\mathrm{C}$, those in the upper tertile $(T 3,0.80-3.98 \mathrm{mmol} / \mathrm{L})$ were positively associated with poor functional outcomes compared to patients in the lower tertile $(T 1,-0.91-0.13 \mathrm{mmol} / \mathrm{L})(\mathrm{OR} 2.56,95 \% \mathrm{Cl} 1.22-5.36, p=0.013)$. The risk of poor functional outcome increased significantly with $\Delta$ LDL-C tertile $(P$-trend $=0.010)$.
\end{abstract}

Conclusions: In AIS patients who underwent reperfusion therapy, the decrease in LDL-C level during hospitalization was significantly associated with poor functional outcomes at 90 days.

Keywords: Low-density lipoprotein cholesterol, Change, Acute ischemic stroke, Reperfusion therapy, Outcome

\footnotetext{
* Correspondence: grongpeng@126.com; dr.bowu@hotmail.com

${ }^{\dagger}$ Ting Cui and Changyi Wang contributed equally to this work.

'Center of Cerebrovascular Diseases, Department of Neurology, West China

Hospital, Sichuan University, No.37 Guo Xue Xiang, Sichuan 610041 Chengdu,

China

Full list of author information is available at the end of the article
}

(c) The Author(s). 2021 Open Access This article is licensed under a Creative Commons Attribution 4.0 International License, which permits use, sharing, adaptation, distribution and reproduction in any medium or format, as long as you give appropriate credit to the original author(s) and the source, provide a link to the Creative Commons licence, and indicate if changes were made. The images or other third party material in this article are included in the article's Creative Commons licence, unless indicated otherwise in a credit line to the material. If material is not included in the article's Creative Commons licence and your intended use is not permitted by statutory regulation or exceeds the permitted use, you will need to obtain permission directly from the copyright holder. To view a copy of this licence, visit http://creativecommons.org/licenses/by/4.0/ The Creative Commons Public Domain Dedication waiver (http://creativecommons.org/publicdomain/zero/1.0/) applies to the data made available in this article, unless otherwise stated in a credit line to the data. 


\section{Background}

The association between low-density lipoprotein cholesterol (LDL-C) and outcomes in acute ischemic stroke (AIS) patients remains controversial [1-11]. The inconsistent results might be explained by oxidative stress. Since AIS patients may suffer from enhanced free-radical damage after reperfusion therapy [12, 13], focusing on patients with reperfusion therapy might clarify the role of LDL-C. However, previous studies on the association between LDL-C level and outcomes in AIS patients with reperfusion therapy failed to reach a consensus [5-8]. The conflicting conclusions may be due to the single measurement of LDL-C.

Some studies found that serum LDL-C levels decreased after the onset of AIS [14-18]. Under oxidative stress, low-density lipoprotein (LDL) gets oxidized into oxidized low-density lipoprotein (oxLDL) [19]. The extent of decreased LDL-C may reflect the degree of increased oxLDL, which may indicate the severity of oxidative stress [20] and is positively associated with poor functional outcomes [21-24]. Therefore, a more sensitive marker may be the change in serum LDL-C during hospitalization [25].

However, there is uncertainty on the association between LDL-C change and outcomes in patients with reperfusion therapy. In this study, we aimed to explore the association between changes in LDL-C levels and functional outcomes in these patients.

\section{Methods}

\section{Study population}

This is a retrospective study. AIS patients admitted to Neurology Department, West China Hospital were consecutively enrolled between 1st June 2018 and 31st January 2021. AIS was diagnosed based on clinical manifestation and brain image [26]. Patients were included as follows: (1) underwent reperfusion therapy within $6 \mathrm{~h}$ after symptom onset, including intravenous thrombolysis with alteplase and/or endovascular thrombectomy (including mechanical or thrombus aspiration thrombectomy, or both, with or without intra-arterial alteplase infusion), and (2) LDL-C levels were measured at emergency department immediately after admission and at least on another occasion during hospitalization. The exclusion criteria were as follows: (1) premorbid modified Rankin scale [mRS] scores $>1$, (2) younger than 18 years, (3) had a liver injury that may affect serum lipid levels [15], or (4) malignancy. We obtained informed consent from each patient or their relative. The Scientific Research Department of West China Hospital approved this study.

\section{Baseline data}

Data on demographics (age, gender), level of neurological severity (according to the National Institute of
Health Stroke Scale [NIHSS] score), risk factors (atrial fibrillation, hypertension, hyperlipidemia, diabetes mellitus, smoking status, and coronary heart diseases), laboratory results (white blood cell, glucose, TG, TC, HDL, and LDL-C), and the interval between stroke onset and emergency department were documented at admission. The interval between stroke onset and admission measurement of LDL-C and the interval between admission and follow-up measurement of LDL-C during hospitalization were also documented. Serum LDL-C was measured by the automatic biochemistry analyzer (Roche Cobas 8000) [27]. The Trial of Org 10,172 in Acute Stroke Treatment (TOAST) classification system was conducted to identify stroke subtypes [28].

\section{Outcome}

All patients were followed up by telephone or interview at 90 days to evaluate their functional outcomes blinded to their LDL-C levels. We used the modified Rankin Scale (mRS) to measure functional outcomes at 90 days [29]. Poor functional outcome was defined as mRS score $>2$ [29].

\section{Statistical analysis}

Continuous variables were reported as means with standard deviations (SD) for normally distributed parameters or medians with interquartile range (IQR) for non-normally distributed parameters. Frequencies or percentages were used to describe categorical variables. Descriptive analyses of study population baseline characteristics and 90-day outcomes were reported for groups using the $\mathrm{X}^{2}$ test or Fisher's exact test for categorical data, the Student's t-test, and the Mann-Whitney U test for continuous variables as appropriate. Significant confounders were defined as variables within $p<0.10$ in univariate analysis. The change of LDL-C level $(\Delta \mathrm{LDL}-\mathrm{C})$ was calculated by subtracting the lowest LDL-C among all measurements during hospitalization from the admission LDL-C: a positive $\triangle \mathrm{LDL}-\mathrm{C}$ indicated LDL-C decreased during hospitalization, and a negative $\triangle \mathrm{LDL}-\mathrm{C}$ indicated an increase in LDL-C level. Multivariate logistic regression models were used to determine associations between $\triangle \mathrm{LDL}-\mathrm{C}$ and outcome. To further explore the associations, we did trend analyses by categorizing $\triangle$ LDL-C into tertiles [30]. Trends across tertiles ( $P$ trend) of $\triangle \mathrm{LDL}-\mathrm{C}$ were determined by entering the median value of $\triangle \mathrm{LDL}-\mathrm{C}$ in each category as a continuous variable [31]. Data were reported as odds ratios (OR) and $95 \%$ confidence intervals $(\mathrm{CI})$. A two-sided $P$ value less than 0.05 was considered statistically significant. All analyses were performed using IBM SPSS Statistics (25.0; IBM, Armonk, NY, USA). 


\section{Results}

\section{Baseline characteristics and outcome}

As shown in Fig. 1, a total of 640 AIS patients underwent reperfusion therapy in our center, there were $24.6 \%$ (158/ 640) patients missed LDL-C levels or outcome follow-up, we compared included patients to these patients, and we found that there were no significant differences in demographic parameters (age and gender), vascular risk factors (diabetes, atrial fibrillation, current smoking, and coronary heart diseases), baseline NIHSS score, TOAST classification, and reperfusion therapy method between two groups, except for more patients with prior history of stroke and hypertension among the included group (Table S1 in supplementary materials). Finally, a total of 432 patients (mean age $69.2 \pm 13.5$ years, $54.6 \%$ males) were included. As shown in Table 1, the mean admission LDL-C level was $2.55 \pm 0.93 \mathrm{mmol} / \mathrm{L}$, the mean lowest LDL-C level during hospitalization was $2.00 \pm 0.88 \mathrm{mmol} / \mathrm{L}$, and the median $\triangle \mathrm{LDL}-\mathrm{C}$ was $0.43 \mathrm{mmol} / \mathrm{L}$ (IQR $0.08-0.94 \mathrm{mmol} / \mathrm{L})$. The median interval time between stroke onset and emergency department was $2.5 \mathrm{~h}$ (IQR 1.8-3.0 h). The median interval time between admission and the lowest LDL-C measurement during hospitalization was 3.1 d (IQR 0.8-6.6 d). For most patients (357/432, 82.6\%), LDL-C levels decreased during hospitalization. A total of 263 (60.9\%) patients had poor 90-day functional outcomes.

\section{Association between admission LDL-C and outcome}

Age, sex, baseline NIHSS score, atrial fibrillation, current smoking, drinking consumption, TOAST classification, serum glucose, reperfusion therapy method, and the interval between admission LDL-C and the lowest LDLC during hospitalization were significantly correlated with poor outcomes in univariate analysis (Table 2). There was no significant association between admission LDL-C level and functional outcome at 90 days when LDL-C level was regarded as a continuous variable (OR $1.03,95 \%$ CI $0.81-1.31, p=0.802$ ), or categorical variable (T3 vs. T1, OR 0.97, $95 \%$ CI $0.55-1.71, p=0.919$, Table 3).

\section{Association between $\triangle \mathrm{LDL}-\mathrm{C}$ and outcome}

When $\triangle \mathrm{LDL}-\mathrm{C}$ was regarded as a continuous variable, $\triangle$ LDL-C was significantly associated with poor functional outcome at 90 days in univariate analysis (OR 1.55, $95 \%$ CI 1.12-2.15, $p=0.009$, Table 4). After adjusting for confounding variables, the association between $\triangle \mathrm{LDL}-\mathrm{C}$ and the poor outcome remained significant (OR 1.80, $95 \%$ CI 1.12-2.91, $p=0.016)$.

When $\triangle \mathrm{LDL}-\mathrm{C}$ was regarded as a categorical variable, patients in the upper tertile (T3, 0.80-3.98 $\mathrm{mmol} / \mathrm{L}$ ) had a higher risk of poor outcome than those in the lower tertile (T1, $-0.91-0.13 \mathrm{mmol} / \mathrm{L})$ in univariate analysis (OR 1.92, $95 \%$ CI 1.15-3.20, $p=0.012$ ). After adjusting for confounding variables, the association between $\triangle \mathrm{LDL}-\mathrm{C}$ and the poor outcome remained significant (OR 2.56, $95 \%$ CI 1.22-5.36, $p=0.013$ ). The risk of poor functional outcome increased significantly with $\triangle \mathrm{LDL}-\mathrm{C}$ tertile $(P$-trend $=0.010)$.

640 AIS patients with reperfusion therapy

were consecutively enrolled

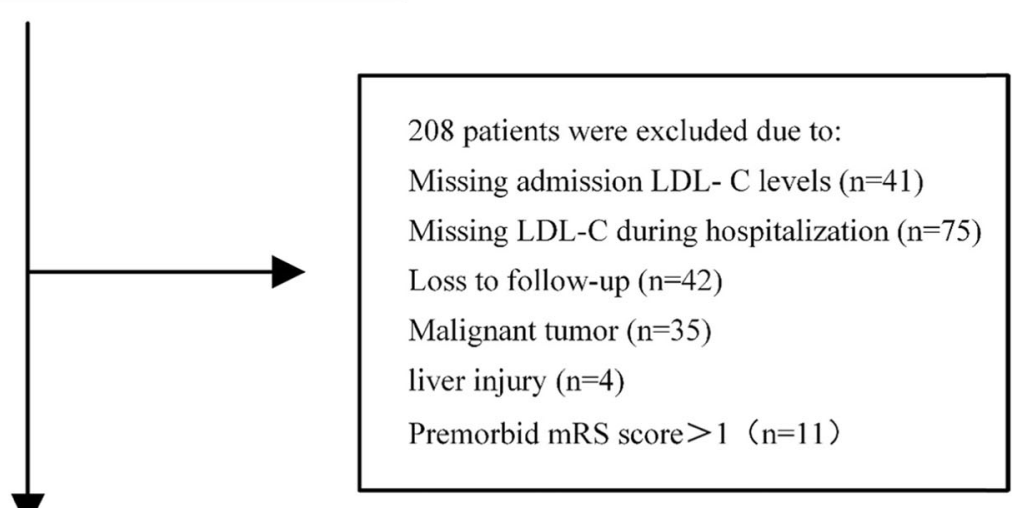

432 patients were included in study analysis

Fig. 1 Patients' inclusion flowchart. AIS, acute ischemic stroke; LDL-C, low-density lipoprotein cholesterol; mRS, modified Rankin Scale; ALT, alanine aminotransferase; AST, aspartate aminotransferase 
Table 1 Patient characteristics stratified by functional outcome at 90 days

\begin{tabular}{|c|c|c|c|c|}
\hline Variables & $\begin{array}{l}\text { Overall } \\
(n=432)\end{array}$ & $\begin{array}{l}\text { Good functional } \\
\text { outcome } \\
(n=169)\end{array}$ & $\begin{array}{l}\text { Poor functional } \\
\text { outcome } \\
(n=263)\end{array}$ & $P$ value \\
\hline Age, years, mean (SD) & $69.2(13.5)$ & 64.9 (13.9) & $72.0(12.5)$ & $<0.001$ \\
\hline Male, n (\%) & $236(54.6)$ & $109(64.4)$ & $127(48.3)$ & $<0.001$ \\
\hline Hypertension, n (\%) & $259(60.0)$ & $95(56.2)$ & $164(62.4)$ & 0.203 \\
\hline Diabetes, n (\%) & $99(22.9)$ & $34(20.1)$ & $65(24.7)$ & 0.267 \\
\hline hyperlipemia, n (\%) & $34(7.9)$ & $13(7.7)$ & $21(8.0)$ & 0.912 \\
\hline Atrial fibrillation, n (\%) & $216(50.0)$ & $63(37.3)$ & $133(58.2)$ & $<0.001$ \\
\hline Valvular heart diseases, n (\%) & $74(17.1)$ & $25(14.8)$ & $49(18.6)$ & 0.301 \\
\hline Coronary heart diseases, n (\%) & $63(14.6)$ & $22(13.0)$ & $41(15.6)$ & 0.460 \\
\hline Previous stroke, n (\%) & $39(9.0)$ & $12(7.1)$ & $27(10.3)$ & 0.263 \\
\hline Current smoking, n (\%) & $107(24.8)$ & $52(30.8)$ & $55(20.9)$ & 0.021 \\
\hline Alcohol consumption, n (\%) & $100(23.1)$ & $52(30.8)$ & $51(19.4)$ & 0.021 \\
\hline Statin use before admission, n (\%) & $39(9.0)$ & $14(8.3)$ & $25(9.5)$ & 0.665 \\
\hline Baseline NIHSS, median (Q1-Q3) & $14(9-18)$ & $9(6-14)$ & $15(12-20)$ & $<0.001$ \\
\hline LDL-C, mmol/L, mean (SD) & $2.55(0.93)$ & $2.59(0.91)$ & $2.53(0.95)$ & 0.496 \\
\hline $\mathrm{HDL}, \mathrm{mmol} / \mathrm{L}$, mean (SD) & $1.27(0.42)$ & $1.25(0.49)$ & $1.29(0.36)$ & 0.332 \\
\hline TG, mmol/L, median (Q1-Q3) & $1.24(0.87-1.89)$ & $1.20(0.85-1.94)$ & $1.20(0.88-1.81)$ & 0.566 \\
\hline $\mathrm{TC}, \mathrm{mmol} / \mathrm{L}$, mean (SD) & $4.23(1.13)$ & $4.22(1.13)$ & $4.23(1.13)$ & 0.966 \\
\hline Serum glucose, mmol/L, mean (SD) & $7.53(6.49-9.18)$ & $7.96(2.76)$ & $8.57(3.04)$ & 0.035 \\
\hline White blood cell, ${ }^{a} 10 \wedge 9 / L$, mean (SD) & $8.47(3.19)$ & $8.23(2.77)$ & $8.62(3.43)$ & 0.207 \\
\hline TOAST classification, n (\%) & & & & $<0.001$ \\
\hline Large-artery Atherosclerosis & $139(32.2)$ & $59(34.9)$ & $80(30.4)$ & \\
\hline Cardio-embolism & 192(44.4) & $57(33.7)$ & $135(51.3)$ & \\
\hline Lacunar & $28(6.5)$ & $22(13.0)$ & $6(2.3)$ & \\
\hline Other & $13(3.0)$ & $7(4.1)$ & $6(2.3)$ & \\
\hline Undetermined & $60(13.9)$ & $24(14.2)$ & $36(13.7)$ & \\
\hline Reperfusion therapy method, n (\%) & & & & 0.092 \\
\hline thrombolysis only & $124(28.7)$ & $58(34.3)$ & $66(25.1)$ & \\
\hline thrombectomy only & $210(48.6)$ & $70(41.4)$ & $140(53.2)$ & \\
\hline thrombolysis and thrombectomy & $98(22.7)$ & $41(24.3)$ & $57(21.7)$ & \\
\hline Statin use during hospitalization, $\mathrm{n}(\%)$ & $263(60.9)$ & $103(60.9)$ & $160(60.8)$ & 0.982 \\
\hline $\begin{array}{l}\text { Interval between stroke onset and emergency } \\
\text { department, h, median (Q1-Q3) }\end{array}$ & $2.5(1.8-3.0)$ & $2.3(2.0-3.0)$ & $2.5(1.7-3.5)$ & 0.610 \\
\hline $\begin{array}{l}\text { Interval between stroke onset and admission } \\
\text { measurement of LDL-C, h, median (Q1-Q3) }\end{array}$ & $3.1(2.2-3.9)$ & $3.1(2.1-3.8)$ & $3.1(2.1-3.8)$ & 0.685 \\
\hline $\begin{array}{l}\text { Interval between admission and follow-up } \\
\text { measurement of } L D L-C, d \text {, median (Q1-Q3) }\end{array}$ & $3.1(0.8-6.6)$ & $1.7(0.6-6.4)$ & $3.4(1.0-7.1)$ & 0.008 \\
\hline${ }^{2} \Delta \mathrm{LDL}-\mathrm{C}, \mathrm{mmol} / \mathrm{L}$, median (Q1-Q3) & $0.43(0.08-0.94)$ & $0.28(0.07-0.78)$ & $0.52(0.10-1.03)$ & 0.009 \\
\hline $\begin{array}{l}\text { The lowest LDL-C during hospitalization, } \\
\text { mmol/l, median (Q1-Q3) }\end{array}$ & $1.92(1.38-2.44)$ & $2.11(1.48-2.69)$ & $1.83(1.34-2.32)$ & 0.002 \\
\hline LDL-C variation, n (\%) & & & & 0.542 \\
\hline decreased $(\Delta \mathrm{LDL}-\mathrm{C}>0)$ & $357(82.6)$ & $142(84.0)$ & $215(81.7)$ & \\
\hline increased $(\Delta \mathrm{LDL}-\mathrm{C} \leq 0)$ & $75(17.4)$ & $27(16.0)$ & $48(18.3)$ & \\
\hline
\end{tabular}

SD standard deviation, $L D L-C$ low-density lipoprotein cholesterol, $\triangle L D L-C$ the change of low-density lipoprotein cholesterol during hospitalization, NIHS $S$ National Institutes of Health Stroke Scale, TOAST the Trial of Org 10,172 in Acute Stroke Treatment

${ }^{a} \Delta L D L-C$ was calculated by subtracting the lowest LDL-C among all measurements during hospitalization from the admission LDL-C 
Table 2 Univariable logistic regression analysis of variables associated with poor functional outcome

\begin{tabular}{|c|c|c|}
\hline Variable & $\begin{array}{l}\text { Unadjusted odds ratio } \\
\text { (95\% confidence interval) }\end{array}$ & $\begin{array}{l}p- \\
\text { value }\end{array}$ \\
\hline$\overline{\text { Age }}$ & $1.04(1.03,1.06)$ & $\begin{array}{l}< \\
0.001\end{array}$ \\
\hline Male & $0.51(0.35,0.77)$ & 0.001 \\
\hline Hypertension & $1.29(0.87,1.91)$ & 0.204 \\
\hline Diabetes & $1.30(0.82,2.08)$ & 0.268 \\
\hline hyperlipemia & $1.04(0.51,2.14)$ & 0.912 \\
\hline Atrial fibrillation & $2.34(1.57,3.48)$ & $\begin{array}{l}< \\
0.001\end{array}$ \\
\hline Valvular heart diseases & $1.32(0.78,2.23)$ & 0.302 \\
\hline coronary heart diseases & $1.23(0.71,2.16)$ & 0.460 \\
\hline Statin use before admission & $1.16(0.59,2.31)$ & 0.666 \\
\hline Previous stroke & $1.50(0.74,3.04)$ & 0.265 \\
\hline Current smoking & $0.60(0.38,0.93)$ & 0.021 \\
\hline Alcohol consumption & $0.59(0.38,0.93)$ & 0.022 \\
\hline Baseline NIHSS score & $1.17(1.12,1.21)$ & $\begin{array}{l}< \\
0.001\end{array}$ \\
\hline HDL upon admission & $1.28(0.78,2.10)$ & 0.334 \\
\hline TG upon admission & $0.92(0.78,1.09)$ & 0.333 \\
\hline TC upon admission & $1.00(0.85,1.19)$ & 0.966 \\
\hline Serum glucose & $1.08(1.00,1.17)$ & 0.038 \\
\hline White blood cell & $1.04(0.98,1.11)$ & 0.208 \\
\hline \multicolumn{3}{|l|}{ TOAST classification } \\
\hline Large-artery Atherosclerosis & Reference & \\
\hline Cardio-embolism & $1.75(1.11,2.76)$ & 0.017 \\
\hline Lacunar & $0.20(0.08,0.53)$ & 0.001 \\
\hline Other & $0.63(0.20,1.98)$ & 0.431 \\
\hline Undetermined & $1.11(0.60,2.05)$ & 0.748 \\
\hline \multicolumn{3}{|l|}{ Reperfusion therapy method } \\
\hline thrombolysis only & Reference & \\
\hline thrombectomy only & $1.76(1.12,2.77)$ & 0.015 \\
\hline thrombolysis and thrombectomy & $1.22(0.72,2.09)$ & 0.463 \\
\hline Statin use during hospitalization & $0.98(0.67,1.48)$ & 0.995 \\
\hline $\begin{array}{l}\text { Interval between stroke onset and } \\
\text { emergency department }\end{array}$ & $1.05(0.89,1.24)$ & 0.546 \\
\hline $\begin{array}{l}\text { Interval between stroke onset and } \\
\text { admission measurement of LDL-C }\end{array}$ & $1.04(0.89,1.21)$ & 0.616 \\
\hline $\begin{array}{l}\text { Interval between admission and } \\
\text { follow-up measurement of LDL-C }\end{array}$ & $1.06(1.01,1.12)$ & 0.023 \\
\hline
\end{tabular}

NIHSS National Institutes of Health Stroke Scale, TOAST the Trial of Org 10,172 in Acute Stroke Treatment

\section{Discussion}

We found that the admission LDL-C was not associated with functional outcomes at 90 days. For most AIS patients who underwent reperfusion therapy, LDL-C decreased during hospitalization. The decrease of LDL-C during hospitalization was associated with poor 90-day functional outcomes. We suggested that the magnitude
Table 3 Multivariate logistic regression analysis between admission LDL-C and poor functional outcome ${ }^{a}$

\begin{tabular}{|c|c|c|}
\hline Variable & $\begin{array}{l}\text { Non-adjusted } \\
\text { model }\end{array}$ & Adjusted model \\
\hline $\begin{array}{l}\text { Admission LDL-C, } \\
\mathrm{mmol} / \mathrm{L}\end{array}$ & $0.93(0.76,1.14), 0.496$ & $1.03(0.81,1.31), 0.802$ \\
\hline \multicolumn{3}{|l|}{$\begin{array}{l}\text { Admission LDL-C } \\
\text { tertiles, mmol/L }\end{array}$} \\
\hline $\mathrm{T} 1(0.74-2.15)$ & Reference & Reference \\
\hline $\mathrm{T} 2(2.16-2.80)$ & $1.31(0.81,2.12), 0.271$ & $1.62(0.92,2.85), 0.096$ \\
\hline T3(2.81-9.61) & $0.82(0.51,1.31), 0.404$ & $0.97(0.55,1.71), 0.919$ \\
\hline \multicolumn{3}{|c|}{$\begin{array}{l}\text { Adjusted model: adjusted for age, sex, atrial fibrillation, Current smoking, } \\
\text { drinking consumption, baseline NIHSS score, Serum glucose, TOAST } \\
\text { classification, and reperfusion therapy method } \\
\text { LDL-C low-Density Lipoprotein Cholesterol, NIHSS National Institutes of Health } \\
\text { Stroke Scale, TOAST the Trial of Org 10,172 in Acute Stroke Treatment } \\
\text { a Results for each model are presented as odds ratio ( } 95 \% \text { confidence } \\
\text { interval), } p \text {-value }\end{array}$} \\
\hline
\end{tabular}

of decrease in LDL-C during hospitalization may reflect the severity of oxidative stress in the acute phase of AIS generated by ischemic stroke and/or brain tissue reperfusion, which might be positively associated with poor 90-day functional outcome in AIS patients with reperfusion therapy.

There was a discrepancy in the prognostic significance between LDL-C level and outcomes in AIS patients [1-11]. Some studies found that higher LDL-C level was associated with poor outcomes in AIS patients [1-3], while some studies found that lower LDL-C was associated with poor outcome in AIS patients [4, 5], others failed to find a significant association between LDL-C and outcome [6-11]. The inconsistent results might be explained by differences in sample size, patient selection, potential confounder, outcome assessment, and different measurement times of LDL-C. Several studies suggested that LDL got oxidized into oxLDL under oxidative stress [19], and oxLDL may contribute to exacerbate free-radical damage in the acute phase of AIS [20, 32-35]. Since AIS patients with reperfusion therapy could suffer from enhanced oxidative injury [12], focusing on these patients might clarify the role of LDL-C.

However, previous studies on the association between LDL-C level and outcomes in AIS patients who underwent reperfusion therapy were rare, and these conclusions failed to reach a consensus [5-8]. Previous studies of AIS patients with thrombolytic therapy failed to find an association between baseline LDL-C and outcome [6-8], which was in line with our study. Recently, a retrospective study involving 174 AIS patients with endovascular thrombectomy (EVT) therapy found that a higher LDL-C level at admission was independently associated with favorable functional outcomes at 3 months [5]. The conflicting results in AIS patients 
Table 4 Multivariate logistic regression analysis between $\Delta \mathrm{LDL}-\mathrm{C}$ and poor functional outcome ${ }^{\mathrm{a}}$

\begin{tabular}{llll}
\hline Variable & Non-adjusted model & Adjusted model 1 & Adjusted model 2 \\
\hline$\Delta L D L-C$, mmol/I & $1.55(1.12,2.15), 0.009$ & $1.79(1.11,2.89), 0.017$ & $1.80(1.12,2.91), 0.016$ \\
$\Delta L D L-C$ tertiles, mmol/I & & & \\
T1 (-0.91-0.13) & Reference & Reference & Reference \\
T2 $(0.14-0.79)$ & $1.03(0.65,1.64), 0.888$ & $1.23(0.70,2.18), 0.473$ & $1.24(0.70,2.19), 0.470$ \\
T3 $(0.80-3.98)$ & $1.92(1.15,3.20), 0.012$ & $2.56(1.22,5.35), 0.013$ & $2.56(1.22,5.36), 0.013$ \\
$P$-trend & 0.007 & 0.010 & 0.010 \\
\hline
\end{tabular}

Adjusted model 1: adjusted for age, sex, atrial fibrillation, Current smoking, drinking consumption, baseline NIHSS score, Serum glucose, TOAST classification, reperfusion therapy method, and interval between admission and follow-up measurement of LDL-C

Adjusted model 2: adjusted for variables in model 1 and statin use during hospitalization

LDL-C low-density lipoprotein cholesterol, $\triangle L D L-C$ the change of low-density lipoprotein cholesterol during hospitalization, NIHSS National Institutes of Health Stroke Scale, TOAST the Trial of Org 10,172 in Acute Stroke Treatment

${ }^{a}$ Results for each model are presented as odds ratio (95\% confidence interval), $p$-value

with reperfusion therapy may be due to the single measurement of LDL-C.

Previous studies suggested that LDL-C levels showed a decreased trend during the acute phase of AIS [14-18]. However, only one study investigated the association between LDL-C change and outcomes in AIS patients [25]. This multicenter study of 676 AIS patients found that increased LDL-C was associated with poor outcomes at discharge [25]. For most patients (566/676, 83.7\%), LDL-C levels decreased during hospitalization in this study, but it did not clarify the association between decreased LDL-C and outcome further. In the current study, we also found that for most patients (357/432, 82.6\%), LDL-C levels decreased during hospitalization, and decreased LDL-C level was significantly associated with poor 90-day functional outcome in AIS patients with reperfusion therapy.

Though the underlying mechanism of the association between $\triangle \mathrm{LDL}-\mathrm{C}$ and outcome remains unclear, it could be explained as follows: LDL-C gets oxidized into oxLDL under oxidative stress [19] and oxLDL is the major marker of oxidative stress [20,32-34]. Previous studies found that high oxLDL is positively associated with poor functional outcomes in AIS patients [21-23]. Therefore, we speculated that the increased oxLDL level may be associated with decreased LDL-C level during hospitalization, the extent of decreased LDL-C may reflect the degree of increased oxLDL, which may indicate the severity of oxidative stress and contribute to poor functional outcomes. Although the specific mechanism of $\triangle \mathrm{LDL}-\mathrm{C}$ level during hospitalization remains unclear, during the oxidative challenge, LDL-C gets oxidized into oxLDL [19], which contributes to free-radical damage [20,32-35] and poor outcome [21-23].

A study of 3019 AIS /TIA patients from the Clopidogrel in High-Risk Patients with Acute Non-Disabling Cerebrovascular Events (CHANCE) trial found that higher levels of ox-LDL and ox-LDL/LDL significantly increased the risk of poor functional outcome in AIS patients [21], which may provide evidence to support our hypothesis. Of course, more studies of high quality are needed to verify the above hypothesis.

From a clinical point of view, since LDL-C is a widely available biomarker and is measured frequently, our findings might help clinicians to identify AIS patients who underwent reperfusion therapy at risk of 90-day poor functional outcome and guide therapy properly, besides there was no additional financial burden for patients' families.

Some limitations should be noted. Firstly, this was a retrospective study and we could not measure oxLDL. Therefore, we could not confirm that the change in LDL-C levels was due to free radical damage; however, a previous study found that the higher levels of oxLDL, and ox-LDL/LDL-C significantly increased the risk of poor outcome [21], which supported our hypothesis. Secondly, we could not measure LDL-C at a specific time for each patient. The results might vary with different testing times [16]. However, in multivariate analysis, we adjusted the interval between admission and followup measurement of LDL-C during hospitalization in Model1, and our results remain significant in the present study. Thirdly, statin therapy could have influenced LDL-C levels. A randomized controlled trial of 60 AIS patients found that LDL-C decreased significantly in statin-treated patients on the 7th day and 3 months [17]. In our study, the median interval between admission and the lowest LDL-C level measurement was 3.1d (IQR $0.8-6.6 \mathrm{~d})$. In addition, there was no significant association between statin usage and outcome in univariate analysis. Moreover, when we further adjusted for this variable in Model 2, our findings remained significant. Therefore, the influence of statin usage may be limited in our study. Fourthly, we measured LDL-C in a non-fasting state, which might influence the results, but a meta-analysis of 68 studies found that the association between LDL-C and ischemic stroke remained even when measured in non-fasting patients [36]. Finally, patients did not conduct a computed tomographic angiography after reperfusion therapy in our 
hospital, therefore we could not evaluate the status of their blood vessels, which might influence our results.

\section{Conclusions}

There was no significant association between admission LDL-C level and outcomes in AIS patients who underwent reperfusion therapy, while the decrease in LDL-C level during hospitalization was positively associated with poor functional outcomes at 90 days.

\section{Abbreviations}

AIS: Acute ischaemic stroke; LDL-C: Low-density lipoprotein cholesterol; $\triangle L D L-C$ : The variation of Low-density lipoprotein cholesterol during hospitalization; NIHSS: National Institutes of Health Stroke Scale; OR: Odds ratio; Cl: Confidence interval; HDL: High-density lipoprotein cholesterol: TC: Total cholesterol; TG: Triglycerides; TOAST: The Trial of ORG 10172 in Acute StrokeTreatment

\section{Supplementary Information}

The online version contains supplementary material available at https:/doi. org/10.1186/s12883-021-02387-2.

Additional file 1: Table S1. Patient characteristics stratified by included patients and excluded patients

\section{Acknowledgements}

Not applicable.

\section{Authors' contributions}

B.W. and R.P. conceived and designed the study. T.C., C.W., Q.Z., A.W., X.Z., S.L. and Y.Y. acquired the data, which T.C. analyzed. T.C. and C.W. aided in data interpretation and wrote the manuscript. All authors were involved in revising the article and approved the final version.

\section{Funding}

This work was supported by National Key Development Plan for Precision Medicine Research (2017YFC0910004), National Natural Science Foundation of China (82071320, 81870937), and the 1.3 .5 project for disciplines of excellence, West China Hospital, Sichuan University (ZYG D18009).

\section{Availability of data and materials}

The data that support the findings of this study are available from the corresponding author upon reasonable request.

\section{Declarations}

Ethics approval and consent to participate

The Scientific Research Department of West China Hospital approved this study and conformed to local and international ethical criteria. We obtained informed consent from each patient or their relative.

\section{Consent for publication}

Participants' consent for publication: Not applicable.

\section{Competing interests}

The authors have no potential conflicts of interest to disclose.

\section{Author details}

${ }^{1}$ Center of Cerebrovascular Diseases, Department of Neurology, West China Hospital, Sichuan University, No.37 Guo Xue Xiang, Sichuan 610041 Chengdu, China. ${ }^{2}$ Departement of Rehabilitation Medicine Center, West China Hospital, Sichuan University, Chengdu, Sichuan, China. ${ }^{3}$ The Second Department of Neurology, Shanxi Provincial People's Hospital, Xi'an, Shanxi, China.
Received: 3 June 2021 Accepted: 1 September 2021

Published online: 16 September 2021

\section{References}

1. Xu T, Zhang JT, Yang M, Zhang H, Liu WQ, Kong Y, et al. Dyslipidemia and outcome in patients with acute ischemic stroke. Biomed Environ Sci. 2014; 27(2):106-10.

2. Perovic E, Mrdjen A, Harapin M, Simundic AM. Short term changes of serum lipids in acute ischemic stroke. Clin Lab. 2016:62(11):2107-13.

3. Stead LG, Vaidyanathan L, Kumar G, Bellolio MF, Brown RD, Jr., Suravaram S, et al. Statins in ischemic stroke: just low-density lipoprotein lowering or more? J Stroke Cerebrovasc Dis. 2009;18(2):124-7.

4. Zhao S, Tian Y, Yan H, Zhang B, Li J, Xing L, et al. Association Between LowDensity Lipoprotein Cholesterol (LDL-C) level and unfavorable outcomes in participants of ischemic stroke without diabetes: a multi-center retrospective study. Med Sci Monit. 2019;25:5934-41.

5. Pikija S, Sztriha LK, Killer-Oberpfalzer M, Weymayr F, Hecker C, Ramesmayer $\mathrm{C}$, et al. Contribution of serum lipid profiles to outcome after endovascular thrombectomy for anterior circulation ischemic stroke. Mol Neurobiol. 2019; 56(6):4582-8

6. Lin TC, Lin YK, Chen Cl, Chan L, Chi NF, Yuan RY, et al. Serum lipid level is not associated with symptomatic intracerebral hemorrhage after intravenous thrombolysis for acute ischemic stroke. PeerJ. 2018;6:e6021.

7. Nardi K, Engelter S, Strbian D, Sarikaya H, Arnold M, Casoni F, et al. Lipid profiles and outcome in patients treated by intravenous thrombolysis for cerebral ischemia. Neurology. 2012:79(11):1101-8.

8. Lin SF, Chao AC, Hu HH, Lin RT, Chen CH, Chan L, et al. Low cholesterol levels increase symptomatic intracranial hemorrhage rates after intravenous thrombolysis: a multicenter cohort validation study. J Atheroscler Thromb. 2019;26(6):513-27.

9. Tziomalos K, Giampatzis V, Bouziana SD, Spanou M, Kostaki S, Papadopoulou $\mathrm{M}$, et al. Prognostic significance of major lipids in patients with acute ischemic stroke. Metab Brain Dis. 2017:32(2):395-400.

10. Li W, Liu M, Wu B, Liu H, Wang LC, Tan S. Serum lipid levels and 3-month prognosis in Chinese patients with acute stroke. Adv Ther. 2008;25(4):329-41.

11. Xing $Y$, An Z, Yu N, Zhao W, Ning X, Wang J. Low density lipoprotein cholesterol and the outcome of acute ischemic stroke: results of a large hospital-based study. Eur Neurol. 2016;76(5-6):195-201.

12. Sun MS, Jin H, Sun X, Huang S, Zhang FL, Guo ZN, et al. Free radical damage in ischemia-reperfusion injury: an obstacle in acute ischemic stroke after revascularization therapy. Oxid Med Cell Longev. 2018;2018:3804979.

13. Tsai NW, Chang YT, Huang CR, Lin YJ, Lin WC, Cheng BC, et al. Association between oxidative stress and outcome in different subtypes of acute ischemic stroke. Biomed Res Int. 2014:2014:256879.

14. Woo J, Lam CWK, Kay R, Wong HY, Teoh R, Nicholls MG. Acute and longterm changes in serum-lipids after acute stroke. Stroke. 1990;21(10):1407-11.

15. Mendez I, Hachinski V, Wolfe B. Serum lipids after stroke. Neurology. 1987; 37(3):507-11.

16. Zitnanova I, Siarnik P, Kollar B, Chomova M, Pazderova P, Andrezalova L, et al. Oxidative stress markers and their dynamic changes in patients after acute ischemic stroke. Oxid Med Cell Longev. 2016;2016:9761697.

17. Montaner J, Chacón P, Krupinski J, Rubio F, Millán M, Molina CA, et al. Simvastatin in the acute phase of ischemic stroke: a safety and efficacy pilot trial. Eur J Neurol. 2008;15(1):82-90.

18. Kutsuna N, Makita K, Goto K, Hirayama K, Kido G, Kagawa Y. Fluctuations of nutrition-associated markers after decompressive hemicraniectomy in middle cerebral artery occlusion patients. Adv Exp Med Biol. 2018;1072:33-8.

19. Adibhatla RM, Hatcher JF. Lipid oxidation and peroxidation in CNS health and disease: from molecular mechanisms to therapeutic opportunities. Antioxid Redox Signal. 2010;12(1):125-69.

20. Uno M, Kitazato KT, Nishi K, Itabe H, Nagahiro S. Raised plasma oxidised LDL in acute cerebral infarction. J Neurol Neurosurg Psychiatry. 2003;74(3):312-6.

21. Wang A, Zhang X, Li S, Zhao X, Liu L, Johnston SC, et al. Oxidative lipoprotein markers predict poor functional outcome in patients with minor stroke or transient ischaemic attack. Eur J Neurol. 2019;26(8):1082-90.

22. Wang A, Dai L, Zhang N, Lin J, Chen G, Zuo Y, et al. Oxidized low-density lipoprotein (LDL) and LDL cholesterol are associated with outcomes of minor stroke and TIA. Atherosclerosis. 2020;297:74-80.

23. Wang A, Yang Y, Su Z, Yue W, Hao H, Ren L, et al. Association of oxidized low-density lipoprotein with prognosis of stroke and stroke subtypes. Stroke. 2017;48(1):91-7. 
24. Tsai N-W, Lee L-H, Huang C-R, Chang W-N, Chang Y-T, Su Y-J, et al. Statin therapy reduces oxidized low density lipoprotein level, a risk factor for stroke outcome. Crit Care. 2014;18(1):R16.

25. Yuan HW, Yang YN, Chen HF, Ji RJ, Lin YJ, Guo RY, et al. Rise in low-density lipoprotein cholesterol during hospitalization is related with poor outcome at discharge in patients with acute ischemic stroke. Cerebrovasc Dis. 2020; 49(1):88-96

26. Tunstall-Pedoe. The World Health Organization MONICA Project (monitoring trends and determinants in cardiovascular disease): a major international collaboration. WHO MONICA Project Principal Investigators. J Clin Epidemiol. 1988:41(2):105-14.

27. Gan W, Liu Y, Luo K-H, Liang S-S, Wang H, Li M, et al. The prevalence change of hyperlipidemia and hyperglycemia and the effectiveness of yearly physical examinations: an eight-year study in Southwest China. Lipids Health Dis. 2018:17(1):70.

28. Adams HP, Bendixen BH, Kappelle L, Biller J, Love BB, Gordon DL, et al. Classification of subtype of acute ischemic stroke. Definitions for use in a multicenter clinical trial. TOAST. Trial of Org 10172 in Acute Stroke Treatment. Stroke. 1993;24(1):35-41.

29. Albers GW, Marks MP, Kemp S, Christensen S, Tsai JP, Ortega-Gutierrez S, et al. Thrombectomy for Stroke at 6 to 16 Hours with Selection by Perfusion Imaging. N Engl J Med. 2018;378(8):708-18.

30. Matthews KA, El Khoudary SR, Brooks MM, Derby CA, Harlow SD, Barinas-Mitchell EJM, et al. Lipid changes around the final menstrual period predict carotid subclinical disease in postmenopausal women. Stroke. 2017:48(1):70-6.

31. Park S-Y, Freedman ND, Haiman CA, Le Marchand L, Wilkens LR, Setiawan WW. Association of coffee consumption with total and cause-specific mortality among nonwhite populations. Ann Intern Med. 2017;167(4):228-35.

32. Lin $Y-L$, Chang $H-C$, Chen T-L, Chang J-H, Chiu W-T, Lin J-W, et al. Resveratrol protects against oxidized LDL-induced breakage of the bloodbrain barrier by lessening disruption of tight junctions and apoptotic insults to mouse cerebrovascular endothelial cells. J Nutr. 2010;140(12):2187-92.

33. Schreurs MPH, Cipolla MJ. Cerebrovascular dysfunction and blood-brain barrier permeability induced by oxidized LDL are prevented by apocynin and magnesium sulfate in female rats. J Cardiovasc Pharmacol. 2014;63(1):33-9.

34. Shie F-S, Neely MD, Maezawa I, Wu H, Olson SJ, Jürgens G, et al. Oxidized low-density lipoprotein is present in astrocytes surrounding cerebral infarcts and stimulates astrocyte interleukin-6 secretion. Am J Pathol. 2004;164(4): 1173-81.

35. Zeljkovic A, Vekic J, Spasojevic-Kalimanovska V, Jelic-Ivanovic Z, BogavacStanojevic N, Gulan B, et al. LDL and HDL subclasses in acute ischemic stroke: prediction of risk and short-term mortality. Atherosclerosis. 2010; 210(2):548-54.

36. Di Angelantonio E, Sarwar N, Perry P, Kaptoge S, Ray KK, Thompson A, et al. Major lipids, apolipoproteins, and risk of vascular disease. JAMA. 2009; 302(18):1993-2000

\section{Publisher's Note}

Springer Nature remains neutral with regard to jurisdictional claims in published maps and institutional affiliations.

Ready to submit your research? Choose BMC and benefit from:
- fast, convenient online submission
- thorough peer review by experienced researchers in your field
- rapid publication on acceptance
- support for research data, including large and complex data types
- gold Open Access which fosters wider collaboration and increased citations
- maximum visibility for your research: over 100M website views per year
At BMC, research is always in progress.
Learn more biomedcentral.com/submissions

